\title{
CHROMOSOMAL ABNORMALITIES AND SEX RATIO IN RABBIT BLASTOCYSTS
}

\author{
N. S. FEGHHEIMER* AND R. A. BEATTY $\dagger$ \\ Department of Genetics, University of Edinburgh, \\ Edinburgh, Scotland
}

(Received 27th April 1973)

Summary. Chromosomal analyses were made of 463 rabbit blastocysts drawn from thirty-nine superovulated does of four strains. Semen containing $1.5 \%$ diploid spermatozoa was taken from one strain only. Artificial insemination was conducted with untreated semen or with centrifuged fractions containing either $0.4 \%$ or $2.9 \%$ diploid spermatozoa. The results indicate that diploid spermatozoa are not a major cause of triploidy among embryos.

The sex ratio scored chromosomally among 434 diploid blastocysts was $48.62( \pm 2.40) \%$ males. With data in the literature incorporated, the average sex ratio among 1077 blastocysts (consistent over three species of mammal) became $50.42( \pm 1.52) \%$ males. These figures may be taken to estimate the primary sex ratio. Sex ratio among blastocysts is extremely stable over various biological and experimental conditions.

Twenty-three $(5 \%)$ of the 463 analysable blastocysts were heteroploid. They comprised eight triploids ( $5 \mathrm{XXX}, 3 \mathrm{XXY}$ ), four trisomics, four diploid/trisomic mosaics, one diploid/monosomic mosaic, four diploid/ tetraploid mosaics, one diploid/triploid mosaic and one triploid/ hexaploid mosaic. 'Clustering' of heteroploids occurred in particular dams. Superovulation had no demonstrable effect on the incidence of heteroploidy. There is some evidence of genetic (dam strain) effects on the incidence.

\section{INTRODUCTION}

Chromosomal abnormalities are an important cause of early embryonic death in eutherian mammals. In man and in agriculturally important or laboratory mammals, estimates of the proportion of chromosomally abnormal zygotes range from $2.5 \%$ in the mouse to $10 \%$ in the pig (review: Fechheimer, 1971). A greater amount and variety of data are required before embryonic loss of this kind can be fully assessed. It is also urgent to understand the aetiology of the meiotic and mitotic errors that give rise to chromosomally abnormal gametes and zygotes, with a view to controlling the incidence of abnormalities.

The rabbit is particularly favourable material. Many individual chromosomes can be identified, the large blastocysts yield many cells for analysis,

* Present address: Department of Dairy Science, The Ohio State University, Columbus, Ohio 43210 , U.S.A.

$\dagger$ Agricultural Research Council Unit of Animal Genetics. 
semen is easily collected from males, and females can be induced to ovulate large numbers of eggs. We had set out originally to study the possible effects of chromosomally abnormal spermatozoa on the incidence of chromosomally abnormal zygotes. In a first phase of this work (Beatty \& Fechheimer, 1972), we had found that young males of the AD strain regularly yielded a particularly high incidence of diploid spermatozoa $(1.5 \%)$. By differential centrifugation of the semen in a dextran-based medium, we had isolated a 'Fraction 2' with $0.4 \%$ diploid spermatozoa near the top of the centrifuge tube, and a 'Fraction 6.5 ' with $2.9 \%$ diploid spermatozoa near the bottom. If they are fertile, diploid spermatozoa should give triploid zygotes. Inseminations of 'fresh' (i.e. noncentrifuged) spermatozoa and of the two centrifuged fractions would be expected to give different incidences of triploid embryos. The results of such inseminations, described in the present work, suggest on the whole that diploid spermatozoa do not give triploid zygotes and other causes of triploidy are indicated. The work also yielded data on the sex ratio among normal (diploid) blastocysts.

\section{MATERIALS AND METHODS}

\section{Animals}

The rabbits, housed and handled uniformly, were drawn from the A, AD, AS and HS strains of Oryctolagus cuniculus bred and maintained at the Department of Genetics over the last 20 years. The inbreeding coefficient is about 0.3 (S. Hayter, unpublished estimate). The HS and AS strains are closely related. All four strains were used as dams, but the sires were drawn only from young $\mathrm{AD}$ strain males, with their high incidence of diploid spermatozoa.

\section{Semen}

Semen was collected with an artificial vagina. The 'Fraction 2' and 'Fraction $6.5^{\prime}$ sperm suspensions extracted from the centrifuge tubes mentioned above were diluted with excess of the Solution $F$ described by Beatty \& Fechheimer (1972), the supernatant was removed after centrifugation, and the 'buttons' of spermatozoa were resuspended in $1 \mathrm{ml}$ Solution $\mathrm{F}$ to give the final inseminates. 'Fresh' semen was diluted $1: 1$ with $0.85 \% \mathrm{NaCl}$ solution to a volume of $1 \mathrm{ml}$. The combinations of these three types of insemination with the four strains of dam inseminated constitute twelve 'treatment groups'.

\section{Superovulation and insemination}

Dams were injected subcutaneously with 0.3 to 0.4 i.u. FSH (Sigma) at about (a) 09.00 or (b) 17.30 hours as follows: 1st day, (b); 2nd and 3rd days, each (a) and (b); 4th day, (a). About 15.00 hours on the 4th day, they were given 25 i.u. LH (Pregnyl, Organon) intravenously, and were inseminated artificially. Excluding the few dams that failed to respond to treatment, the mean number of corpora lutea per dam was twenty-nine (range, two to sixtythree).

\section{Blastocyst collection and preparation}

About $5 \frac{1}{2}$ days after fertilization (i.e. about 09.00 hours on the 6 th day after 
insemination), dams were injected intravenously with $2.5 \mathrm{mg}$ vinblastine sulphate (Eli Lilly) dissolved in $2.5 \mathrm{ml}$ distilled water. (In five of the dams, $20 \mathrm{mg}$ colchicine in $2 \mathrm{ml}$ distilled water were substituted for vinblastine sulphate; this did not appear to affect the results in any way.) Between 1 and $1 \frac{1}{2} \mathrm{hr}$ later, the dams were killed with excess Nembutal, and 8 to $10 \mathrm{ml} \mathrm{Hanks'} \mathrm{balanced}$ salt solution (BSS) or TCM 199 were used to flush the blastocysts from the excised uteri into Petri dishes. Each blastocyst was transferred to a separate 2-ml conical-bottom centrifuge tube containing three drops of the salt solution. Five drops of $0.25 \%$ trypsin $(0.1 \%$ trypsin was used in the initial experiments, but was less satisfactory) in Ca- and Mg-free Hanks' BSS were then added to each tube and the tubes were incubated for 5 to $10 \mathrm{~min}$ in a water bath at $38^{\circ} \mathrm{C}$.

Using a finely drawn pipette, the inner cell mass of each blastocyst was isolated and then converted into a cell suspension by gently drawing it in and out of the pipette. After a brief period in iced water to arrest the activity of the trypsin, the tubes were centrifuged for $5 \mathrm{~min}$ at $1000 \mathrm{rev} / \mathrm{min}(225 \mathrm{~g})$ and then all except one or two drops of the supernatant fluid were carefully removed. The cells were resuspended in the remaining fluid and $1 \mathrm{ml}$ hypotonic solution (1 part calf serum to 3 parts distilled water) was added drop by drop while constantly agitating the contents of the tube by flicking. The hypotonic solution was removed by again centrifuging the tubes and removing most of the fluid. The cells were resuspended in the remaining fluid. Cold fixative (1 part glacial acetic acid to 3 parts methanol) was added a drop at a time while the tubes were constantly being flicked. The fixative was removed by centrifugation and fresh fixative was added. All but five drops of the fixative were now removed, the cells were resuspended and the suspension was transferred one drop at a time on to slides recently removed from iced water and still wet. Slides were dried quickly by vigorous waving, by gentle application of heat from a spirit burner, or by both. Slides were flooded for $9 \mathrm{~min}$ in Giemsa stain (Gurr) diluted 1:19 in Wright's phosphate buffer $\left(\mathrm{Na}_{2} \mathrm{HPO}_{4} 0.205 \mathrm{~g}, \mathrm{KH}_{2} \mathrm{PO}_{4}\right.$ $0.6835 \mathrm{~g}$, distilled water to 1 litre: $\mathrm{pH} 6.45$ to 6.50$)$. Stain was washed from the slides with distilled water. After blotting and air-drying, DePeX and a coverslip were added.

\section{Scanning slides and scoring cells}

Unruptured cells were first located under low power optics, i.e. round cells with well dispersed and sharply defined metaphase chromosomes. With high power, five suitable cells per slide were analysed in a preliminary scoring. Chromosomes were counted and allocated to the groups defined by Issa, Atherton \& Blank (1968). When more than one cell possessed a chromosome number other than 44 , all suitable cells on the slide were analysed, to a maximum of thirty cells. Karyotypes were prepared from representative cells in all blastocysts exhibiting heteroploidy.

\section{RESULTS}

Of the seventy-seven dams used, five were excluded from further consideration (one already pregnant; three without CL; one with unrecorded CL and no 
blastocysts). The remaining seventy-two dams (all with CL) bore an estimated 2074 CL (unrecorded numbers in three dams being estimated from the number of blastocysts). Thirty-nine dams had at least one analysable blastocyst. A total of 737 blastocysts were recovered, of which 191 were unprocessed (mainly for reasons of time), eighty-three were processed but not analysable, and 463 could be analysed.

\section{Fertility}

Fertility was decreased after insemination with treated spermatozoa ('Fraction 2 ' and 'Fraction 6.5') (Table 1). As judged by the percentage of dams bearing

Table 1. Classification of all rabbit dams bearing corpora lutea and of numbers of blastocysts.

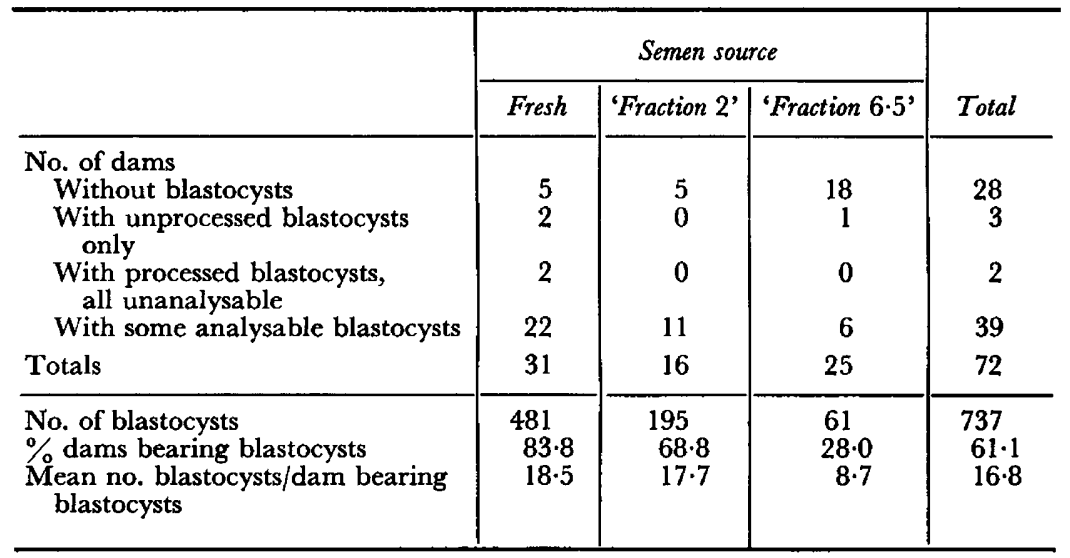

blastocysts and also by the mean number of blastocysts/dam in dams bearing blastocysts, 'Fraction 2' semen appeared less fertile than 'Fresh' semen, while 'Fraction 6.5 ' semen was markedly less fertile than both. 'Fraction 6.5 ' was observed to contain very few spermatozoa.

\section{Chromosomal sex of diploid blastocysts}

Of the 440 diploid blastocysts from thirty-nine dams, 434 could be sexed chromosomally (Table 2). An XY constitution was diagnosed when a single $\mathrm{Y}$ chromosome was present. The XX constitution was diagnosed by absence of a Y chromosome and the presence of 12 chromosomes in the (9 to $13+\mathrm{X})$ group of medium-sized submetacentric chromosomes (see Pl. 1, Fig. 1). The diploid cell line of some mosaics and aneuploids could be sexed chromosomally but these were excluded from the present section.

The relative numbers of XY and XX diploid blastocysts listed in Table 2 show a picture of complete statistical homogeneity. The data were analysed as a single $2 \times 39$ table, and also with partitioning into 'within' and 'between' the twelve treatment groups. Contingency $\chi^{2}$ tests (and also $\chi^{2}$ tests for heterogeneity of departures from an assumed 1:1 ratio) all yielded $P$ values of 0.5 to $\mathbf{0 . 8}$. Additional tests showed no significant effect on sex ratio attributable to 
individual sires (a total of eight were used), to the number of blastocysts/dam (range eleven to fifty-three), nor to age of dam (range 6 to 30 months). Since sex ratio is evidently stable over all levels of the data, it is best estimated from the grand totals of $211 \mathrm{XY}$ and $223 \mathrm{XX}$ blastocysts, i.e. $48.62( \pm 2.40) \%$ male, a figure which does not differ significantly from an assumed 1:1 sex ratio $(P=0.7$ to 0.5$)$.

Table 2. Classification by karyotype of 463 analysable blastocysts from thirty-nine rabbit dams

\begin{tabular}{|c|c|c|c|c|}
\hline \multirow{2}{*}{$\begin{array}{l}\text { 'Treatment groups': } \\
\text { strain of dam and } \\
\text { semen source }\end{array}$} & \multicolumn{3}{|c|}{ Diploid* } & \multirow[t]{2}{*}{ Heteroploid } \\
\hline & $X r$ & $X X$ & Unsexable & \\
\hline A: Fresh & $\begin{array}{l}5 \\
2 \\
5 \\
3 \\
8 \\
6\end{array}$ & $\begin{array}{r}6 \\
2 \\
12 \\
4 \\
3 \\
4\end{array}$ & $\begin{array}{l}0 \\
0 \\
0 \\
0 \\
0 \\
0\end{array}$ & $12 \mathrm{~N} / 3 \mathrm{~N}$ mosaic $(\mathrm{XX} / \mathrm{XXY})$ \\
\hline AD: Fresh & $\begin{array}{r}6 \\
3 \\
0 \\
10 \\
2 \\
7\end{array}$ & $\begin{array}{r}5 \\
4 \\
1 \\
4 \\
1 \\
10\end{array}$ & $\begin{array}{l}0 \\
1 \\
0 \\
0 \\
1 \\
2\end{array}$ & $\begin{array}{l}12 \mathrm{~N}+1(\mathrm{X} ? \mathrm{XY}) \ddagger \\
13 \mathrm{~N}(\mathrm{XXY})\end{array}$ \\
\hline & $\begin{array}{l}6 \\
8\end{array}$ & $\begin{array}{l}7 \\
7\end{array}$ & $\begin{array}{l}0 \\
0\end{array}$ & $12 \mathrm{~N} / 2 \mathrm{~N}-1$ mosaic $(\mathrm{XX}) \dagger$ \\
\hline AS: Fresh & $\begin{array}{l}5 \\
8 \\
2 \\
9\end{array}$ & $\begin{array}{r}5 \\
12 \\
2 \\
7\end{array}$ & $\begin{array}{l}\mathbf{0} \\
\mathbf{0} \\
\mathbf{0} \\
\mathbf{0}\end{array}$ & $\begin{array}{l}12 \mathrm{~N} / 4 \mathrm{~N} \text { mosaic }(\mathrm{XY} / \mathrm{XXYY}) \\
13 \mathrm{~N}(\mathrm{XXY}): 1(2 \mathrm{~N} / 4 \mathrm{~N} \text { mosaic }(\mathrm{XX} / \mathrm{XXXX})\end{array}$ \\
\hline HS: Fresh & $\begin{array}{r}12 \\
5 \\
3 \\
4\end{array}$ & $\begin{array}{r}15 \\
11 \\
6 \\
4\end{array}$ & $\begin{array}{l}1 \\
0 \\
0 \\
0\end{array}$ & $\begin{array}{l}22 \mathrm{~N} / 2 \mathrm{~N}+1 \text { mosaics }(\text { both } \mathrm{XY}) \dagger \\
12 \mathrm{~N} / 2 \mathrm{~N}+1 \text { mosaic }(\mathrm{XX}) \dagger \\
12 \mathrm{~N} / 2 \mathrm{~N}+1 \text { mosaic }(\mathrm{XY}) \dagger\end{array}$ \\
\hline A: Fraction 2 & 1 & 0 & 0 & \\
\hline AD: Fraction 2 & $\begin{array}{r}13 \\
9 \\
1\end{array}$ & $\begin{array}{r}15 \\
12 \\
0\end{array}$ & $\begin{array}{l}0 \\
0 \\
0\end{array}$ & \\
\hline AS: Fraction 2 & $\begin{array}{r}10 \\
4 \\
6\end{array}$ & $\begin{array}{r}11 \\
13 \\
4\end{array}$ & $\begin{array}{l}0 \\
0 \\
0\end{array}$ & $\begin{array}{l}12 \mathrm{~N}+1(\mathrm{XX}) \\
13 \mathrm{~N}(\mathrm{XXX}): 12 \mathrm{~N}+1(\mathrm{XX}): 12 \mathrm{~N}+1(\mathrm{X} ? \mathrm{XY}) \ddagger \\
12 \mathrm{~N} / 4 \mathrm{~N} \text { mosaic }(\mathrm{XX} / \mathrm{XXXX}): 12 \mathrm{~N} / 4 \mathrm{~N} \text { mosaic } \\
\quad(\mathrm{XY} / \mathrm{XXYY})\end{array}$ \\
\hline & 2 & 0 & 0 & \\
\hline HS: Fraction 2 & $\begin{array}{r}15 \\
9 \\
0\end{array}$ & $\begin{array}{r}11 \\
5 \\
2\end{array}$ & $\begin{array}{l}0 \\
0 \\
0\end{array}$ & $\begin{array}{l}13 \mathrm{~N}(\mathrm{XXX}): 13 \mathrm{~N}(\mathrm{XXY}) \\
33 \mathrm{~N}(\mathrm{XXX}): 13 \mathrm{~N} / 6 \mathrm{~N} \text { mosaic }(\mathrm{XXX} / \mathrm{XXXXXX})\end{array}$ \\
\hline A: Fraction 6.5 & 1 & 0 & 1 & \\
\hline AD: Fraction 6.5 & $\begin{array}{l}7 \\
3 \\
0\end{array}$ & $\begin{array}{l}3 \\
4 \\
1\end{array}$ & $\begin{array}{l}\mathbf{0} \\
\mathbf{0} \\
\mathbf{0}\end{array}$ & \\
\hline AS: Fraction 6.5 & 10 & 10 & 0 & \\
\hline HS: Fraction 6.5 & 1 & $\mathbf{0}$ & 0 & \\
\hline Totals & 211 & 223 & 6 & 23 \\
\hline
\end{tabular}

* 423 with $>$ five cells scored/blastocyst. Eleven with two to four cells scored/blastocyst $(6 \mathrm{XY}, 5 \mathrm{XX})$.

+ The sex chromosome constitution is that of the $2 \mathrm{~N}$ component.

$\ddagger$ The extra chromosome, found in the $(9$ to $13+X)$ group, may therefore have been an $X$. 


\section{Heteroploid blastocysts}

Types of heteroploidy. Of the 463 analysable blastocysts from thirty-nine dams, twenty-three $(4.97 \%)$ were heteroploid. They are listed in Table 2 . There were seven categories of heteroploid, comprising eight triploids $(3 \mathrm{~N})$, one $2 \mathrm{~N} / 3 \mathrm{~N}$ mosaic, one $3 \mathrm{~N} / 6 \mathrm{~N}$ mosaic, four trisomics $(2 \mathrm{~N}+1)$, four diploid/trisomic mosaics $(2 \mathrm{~N} / 2 \mathrm{~N}+1)$, one diploid/monosomic mosaic $(2 \mathrm{~N} / 2 \mathrm{~N}-1)$ and four diploid/tetraploid mosaics $(2 \mathrm{~N} / 4 \mathrm{~N})$. Apart from the $2 \mathrm{~N} / 3 \mathrm{~N}$ mosaic and the $3 \mathrm{~N} / 6 \mathrm{~N}$ mosaic, all categories were represented in both the 'fresh' and 'Fraction 2' series.

'Clustering' effect. The twenty-three heteroploid blastocysts were confined to fourteen of the thirty-nine dams. Five of these fourteen dams each yielded more than one blastocyst of the same type; two $2 \mathrm{~N} / 2 \mathrm{~N}+1$ from one dam; two $3 \mathrm{~N}$ from another; three $3 \mathrm{~N}$ (as well as one $3 \mathrm{~N} / 6 \mathrm{~N}$ ) from another; two $2 \mathrm{~N}+1$ from another; and two $2 \mathrm{~N} / 4 \mathrm{~N}$ from the fifth dam. Three of the fourteen dams each yielded more than one category of heteroploid. Thus 'clustering' seems apparent, but it is impossible to be sure of its reality by mere inspection of the data. The possibility that the proportions of heteroploids are statistically heterogeneous from one dam to another within a treatment group was examined, using exact probability methods. The pooled within-group heterogeneity in the incidence of triploids was significant $(P<0.05)$ (from Fisher's combined statistic, ignoring groups in which no abnormalities were observed). The 'HSFraction 2' treatment group provided the major contribution to the combined statistic. A similar calculation based on the proportion of 'heteroploids other than triploids' yielded no significant dam-to-dam heterogeneity, but it would be unsafe in data based on small numbers to assume that 'non-significance' means 'no real heterogeneity'. We conclude that there is a real dam-to-dam heterogeneity in the proportion of triploid blastocysts, and that heterogeneity in the incidence of other types of heteroploid cannot safely be excluded.

\section{Effects of semen source and of strain of dam}

Nineteen of the twenty-three heteroploid blastocysts (including seven of the eight triploids) came from dams of the closely related AS and HS strains inseminated with 'fresh' or 'Fraction 2' semen. Only four heteroploid blastocysts (including one triploid) came from dams of $\mathrm{A}$ and $\mathrm{AD}$ strains. No heteroploid blastocysts were found after inseminations with 'Fraction 6.5' semen. There may, therefore, be differences in the incidence of heteroploids in general (or triploids in particular), between the strains of dam and between the three

\section{EXPLANATION OF PLATE 1}

Karyotypes of metaphase chromosomes from cells of normal and chromosomally abnormal rabbit blastocysts. All figures are at the same magnification.

Fig. 1. Karyotype from a normal male. Chromosomes are arranged and numbered according to the scheme proposed by Issa et al. (1968).

Fig. 2. Karyotype from a blastocyst with trisomy for a chromosome of group 5 to 8 .

Fig. 3. Karyotype from a blastocyst with trisomy for a chromosome of group 9 to $13+X$.

FIG. 4. Karyotype from a blastocyst with trisomy for a chromosome of group 17 to 18 .

Figs 5 and 6 . Karyotypes from two triploid blastocysts. Fig. 5 illustrates the sex chromosome complement XXY; Fig. 6 illustrates the sex chromosome complement XXX. 


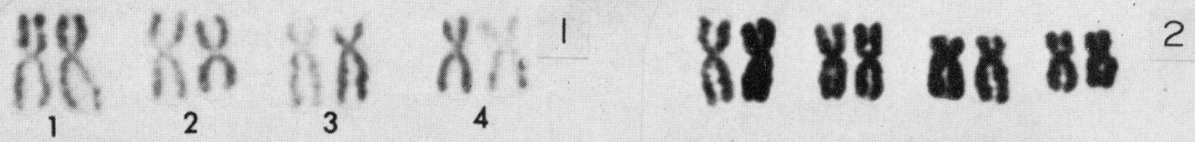

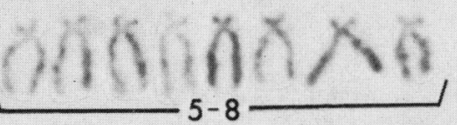

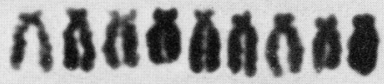

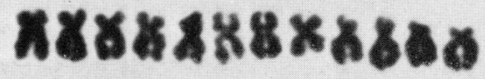 \\ 政为 \\ -14-15_ 16

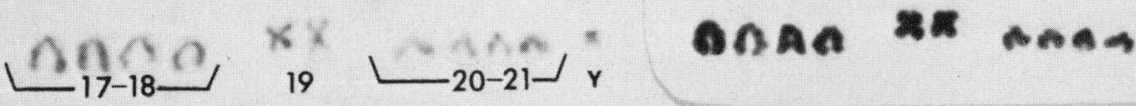 \\ $10 \mu$ \\ $88 x 8 x x^{3}$

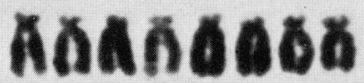 \\ ชหมแกระกตลดล \\ $x \pi x \times$ \\ $x \times$

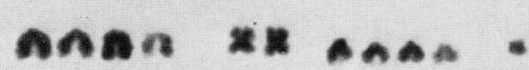 \\ $88888 \times 884$

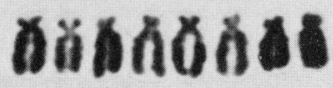

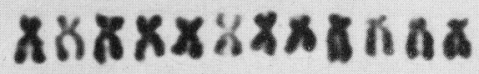 \\ $x \times \times$ xะ

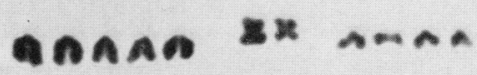

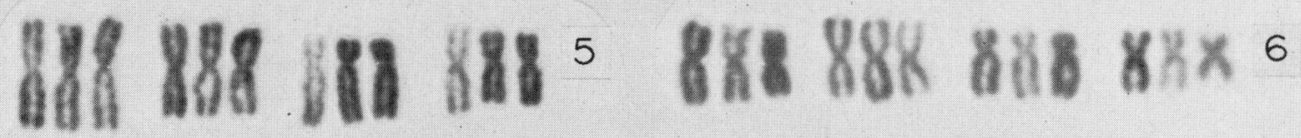

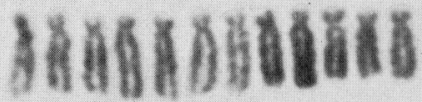

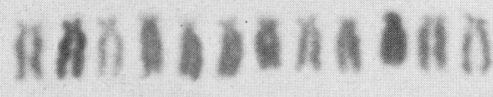

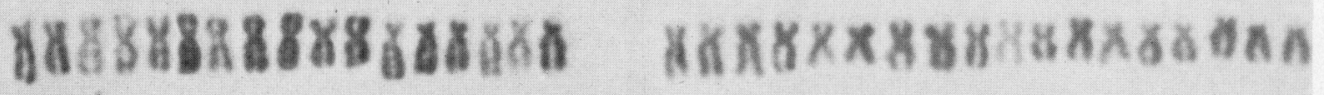
$x 88838 \quad 88=$

$\mathrm{x} \times \mathrm{x} \times \mathrm{A} \pi$

Q)

(Facing p. 336) 
kinds of semen. The 'clustering' effect mentioned above makes it virtually impossible to test formally the significance of strain and semen-source effects, and much more extensive data would be required before such tests became feasible. The strongest conclusion we can draw, and this must be regarded as provisional, is that the incidence of triploids is against expectation, since 'Fraction 2' semen (with $0: 4 \%$ diploid spermatozoa) might have been expected to produce fewer triploids than 'Fraction 6.5' semen (with $2.9 \%$ diploid spermatozoa).

\section{Identification of individual chromosomes}

The results of chromosomal sexing of diploid XX and XY blastocysts have already been described. Five triploids were XXX, three were XXY. The triploid cell line of the $3 \mathrm{~N} / 6 \mathrm{~N}$ mosaic was $\mathrm{XXX}$, that of the $2 \mathrm{~N} / 3 \mathrm{~N}$ mosaic XXY (see Pl. 1, Figs 5 and 6).

Karyograms were made from representative cells of those blastocysts exhibiting trisomy or a trisomic cell line. Chromosomes were arranged and numbered according to the scheme proposed by Issa et al. (1968). The results are included in Table 2. In the eight trisomic cell lines analysed, the extra chromosome was a member of group 17 to 18 (acrocentric) in two cases (Pl. 1, Fig. 4), of group 9 to $13+\mathrm{X}$ (submetacentric) in three cases (PI. 1, Fig. 3), and of group 5 to 8 (subacrocentric) in three cases (Pl. 1, Fig. 2).

\section{DISCUSSION}

Sex ratio among diploid blastocysts

Chromosomal sexing of blastocysts brings us very near in time to an estimate of the primary sex ratio at fertilization. We now list estimates of percentage male blastocysts, with standard errors attached, and the total analysable blastocysts in parentheses. Our estimate of $48.62( \pm 2.40) \%(434)$ for rabbits is close to the Mendelian expectation of $50 \%$ and to a figure of $47.72( \pm 2.59) \%$ males among 373 newly born AS strain rabbits (calculated from Beatty, 1969) and is of the same order as the following estimates calculated or taken from the literature: $54 \cdot 33( \pm 3 \cdot 13) \%(254)$ for the rabbit (Shaver \& Carr, 1967, 1969); $50.00( \pm 2 \cdot 83) \%(312)$ in mice (Vickers, 1969a); $49.35( \pm 5 \cdot 70) \%(77)$ in the pig (McFeely, 1967). In the 16-hr chick blastula, Fechheimer, Lodge \& Miller (1970) demonstrated $49.46( \pm 1.65) \%$ male (918). Some of these estimates were obtained after pooling various sub-groups within the data, differentiated by such factors as strains, delayed fertilization, incidence of diploid spermatozoa, separation of spermatozoa by centrifugation, normal coitus versus artificial insemination, injection of LH and FSH into the dam, or of LH only. Nevertheless, in every case (including the chick) tests showed no significant heterogeneity between sub-groups within groups, the pooled contingency $\chi^{2}$ from the recorded numbers of XY and XX (or ZW and ZZ) being 17.29 on 26 d.f.: $P=0.9$ to $0 \cdot 8$. If we consider the mammalian data only, since it is not clear how to homologize $\mathrm{ZW}$ and $\mathrm{ZZ}$ birds with $\mathrm{XX}$ and $\mathrm{XY}$ mammals, it can also be shown that the four ratios given above in this paragraph are statistically homogeneous, the contingency $\chi^{2}$ being $2 \cdot 175$ on 3 d.f.: $P=0.7$ to 0.5 . 
Thus, sex ratio among mammalian blastocysts appears to be completely stable at all levels of the data, in spite of variations in numerous experimental and biological factors. This justifies a summation of the mammalian data over the three species to yield an estimate of $50.42( \pm 1.52) \%$ males among 1077 blastocysts. Assuming that the same ratio holds only a few days earlier in development, we then have an estimate of the primary sex ratio. The virtually exact agreement with the Mendelian expectation of $50 \%$ makes it wholly unnecessary to imagine that sex ratio might, after all, be abnormal at the time of fertilization, and then regulate to $50 \%$ in the few days required for blastocyst formation. On comparative grounds, we support the argument of Kerr \& Rashad (1966) that some earlier estimates of a grossly abnormal primary sex ratio in man are probably wrong.

\section{Overall incidence of heteroploidy}

Estimates of the frequency of heteroploid blastocysts tend to be minimal. In our work, some mosaics would remain undetected because only five cells per blastocyst were analysed in detail during the preliminary examinations; some heteroploids may have died before recovery; small blastocysts, and particularly those under $1 \mathrm{~mm}$ in diameter, did not usually yield useful preparations and there is some evidence (Hansen-Melander \& Melander, 1971) that heteroploid blastocysts tend to be small; some minor structural rearrangements would have been missed because detailed karyotypic analysis of every blastocyst was not practicable.

The overall incidence of heteroploid blastocysts in the present work, with the number of blastocysts in parentheses, was $4.97 \%$ (463). This is a summation over the not very different separate figures of $4 \cdot 12 \%$ (267) after 'fresh' semen and $6.12 \%(196)$ after centrifuged semen. All our work involved artificial insemination, and injection of dams with both FSH and LH. Figures reconstituted from the relevant part of Shaver \& Carr $(1967,1969)$ were calculated as $1.72 \%$ (58) after normal coitus and $6.85 \%$ (73) after normal coitus with simultaneous $\mathrm{LH}$ administration. The effect of $\mathrm{LH}$ in their work was nonsignificant, and the additional use of artificial insemination and FSH in our work evidently caused no further rise in incidence. Since FSH induces superovulation, the usefulness of this finding in terms of economy in the use of dams is obvious.

\section{Strain differences and the incidence of heteroploid blastocysts}

In man, the phenomenon of 'clustering', i.e. the occurrence within families of two or more individuals possessing chromosomal abnormalities (e.g. Hauschka, Hasson, Goldstein, Koepf \& Sandberg, 1962) has suggested a genetic control of non-disjunction and other errors of cell division. We have statistically significant evidence of 'clustering' within particular rabbit dams. 'Clustering' may reflect a form of genetic control of the incidence of heteroploids, but possible permanent or semi-permanent environmental influences affecting one or both parents cannot be excluded. 'Clustering' has the unfortunate effect of invalidating the statistical basis on which routine calculations of $\chi^{2}$ or of standard errors of means rely. It is for this reason that our second line of 
evidence for genetic control, the apparent effect of the strain of the dam on the incidence of heteroploidy, or of particular kinds of heteroploidy, must be regarded as provisional.

\section{Origin of triploid blastocysts and the rôle of diploid spermatozoa}

These two interrelated subjects are considered together. One objective had been to test whether diploid spermatozoa give rise to triploid eggs. The following arguments suggest that they do not, and the origin of our eight triploids is best ascribed to other causes.

Although the 'clustering' effect vitiates ordinary significance tests, the incidence of triploids after insemination with semen containing $2.9 \%$ diploid spermatozoa was actually less than after insemination with a fraction containing $0.4 \%$ and we, therefore, have no evidence that diploid spermatozoa contribute to the incidence of triploid zygotes.

There is also karyotypic evidence of origin. The numbers of XXX:XXY: XYY triploid blastocysts are 5:3:0 in our data; 3:7:0 in the rabbit after delayed fertilization (Shaver \& Carr, 1967, 1969); 2:0:0 in the mouse after delayed fertilization (Vickers, 1969b); and 2:1:1 in the pig (McFeely, 1967). After implantation, the figures are 1:0:0 in the mouse (Vickers, 1969b), and 26:44:4 in human abortuses (Carr, 1971). Assuming no differential effects on viability or fertility, triploidy can arise by several mechanisms which can be illustrated in terms of the sex chromosomes only. (1) Doubling of the egg chromosome number to $\mathrm{XX}$, giving $\mathrm{XXX}$ and $\mathrm{XXY}$ triploids in equal number. (2) Dispermy with $(\mathrm{X}+\mathrm{X}):(\mathrm{X}+\mathrm{Y}):(\mathrm{Y}+\mathrm{Y})$ spermatozoa in presumed $1: 2: 1$ ratio, giving $1 \mathrm{XXX}: 2 \mathrm{XXY}: 1 \mathrm{XYY}$ triploids. (3) Doubling of chromosome number (assuming pre-reduction) at the first male meiosis, giving only $\mathrm{XY}$ spermatozoa and XXY triploids. (4) Doubling of chromosome number (assuming pre-reduction) at the second male meiosis, giving $\mathrm{XX}: \mathrm{YY}$ spermatozoa in $1: 1$ ratio and $1 \mathrm{XXX}: 1 \mathrm{XYY}$ triploids. The low or zero incidence of XYY triploids in all the above karyotypic data suggest that mechanisms (2) and (4) are not major causes of the incidence of triploidy, and there is no actual evidence that (2) and (4) operate in any of the rodent data. Further, Esnault \& Ortavant (1967) have shown that in the bull the doubling of chromosome number at the first meiosis required for mechanism (3) does not occur. Finally, our major example of 'clustering' (three $3 \mathrm{~N}$ and one $3 \mathrm{~N} / 6 \mathrm{~N}$ among six analysable blastocysts of one dam in one treatment group) could be explained by some particular quality of the dam that favoured the operation of mechanisms (1) and/or (2) (the incidence of diploid spermatozoa being the same for each dam in the group).

Drawing together these various lines of evidence, we conclude that diploid spermatozoa in general are unlikely to contribute significantly to the incidence of triploid zygotes, the evidence against participation by XY and YY spermatozoa being the strongest. The simplest interpretation of our observed numbers of $5 \mathrm{XXX}: 3 \mathrm{XXY}: 0 \mathrm{XYY}$ is that they differ only through sampling error from an expectation of $4: 4: 0$ arising from chromosome doubling in the oocyte; the possibility of a contribution from dispermy cannot be excluded; while diploid spermatozoa probably played little or no part. 


\section{Origin of non-triploid heteroploids}

Euploid mosaics. There were four $2 \mathrm{~N} / 4 \mathrm{~N}$, one $3 \mathrm{~N} / 6 \mathrm{~N}$ and one $2 \mathrm{~N} / 3 \mathrm{~N}$. The $2 \mathrm{~N} / 4 \mathrm{~N}$ were confined to two AS dams, two in each. This evidence of 'clustering' and of a possible genetic (strain) effect on their incidence is supported on comparative grounds by similar evidence in the chick, for which Miller, Fechheimer \& Jaap (1971) reported eighteen euploid mosaics, sixteen of them $2 \mathrm{~N} / 4 \mathrm{~N}$, fifteen of the eighteen being in one hen. In subsequent generations of the same strain of birds, ten more $2 \mathrm{~N} / 4 \mathrm{~N}$ were found, five in eggs from two hens.

In our $2 \mathrm{~N} / 4 \mathrm{~N}$ and $3 \mathrm{~N} / 6 \mathrm{~N}$ mosaics, the sex chromosomes in one component are a simple doubling of those in the other $(2 \mathrm{XX} / \mathrm{XXXX}, 2 \mathrm{XY} / \mathrm{XXYY}$, $1 \mathrm{XXX} / \mathrm{XXXXXX)}$, and we need invoke only the failure of a blastomere to divide following chromosomal replication. The same simple doubling of sex chromosomes in one component applied also to all twenty-eight $2 \mathrm{~N} / 4 \mathrm{~N}$ chick embryos reported by Miller (1971) as well as to a ZZW/ZZZZWW aneuploid. It must be admitted that all cases of simple doubling in a mosaic could be attributed to an accumulation, in a moribund blastocyst, of cells that have undergone chromosomal but not cytoplasmic division.

The $2 \mathrm{~N} / 3 \mathrm{~N}$ mosaic presumably arose from an egg that had undergone 'immediate cleavage' at the first meiotic division (Austin, 1961), this giving in the first place a two-celled oocyte with two haploid sets of chromatids in each half. Two mechanisms described by Beatty (1972) are that one of the cells then extrudes a second polar body and both are entered by a haploid spermatozoon; or that both cells fail to extrude a second polar body and one is entered by a haploid spermatozoon. A further possibility (unlikely, in view of the present work) is that one cell emits a second polar body and is fertilized by a diploid spermatozoon, while the other cell either emits a polar body and is fertilized by a haploid spermatozoon or else emits no polar body and is not entered by a spermatozoon.

Trisomics. The four $2 \mathrm{~N}+1$ trisomics presumably arose by pre-fertilization nondisjunction, giving disomic gametes, since zygote non-disjunction would be more likely to lead to a mosaic. In two blastocysts, the extra chromosome was clearly an autosome of the number 17 to 18 group of acrocentric elements. The extra chromosome in the other two embryos however was in the group containing the $\mathrm{X}$, and the possibility exists that one of these was XXY and one XXX.

When disomic gametes arise after meiotic non-disjunction, simultaneous production of nullosomic gametes would be expected, leading to monosomic zygotes. The absence of the latter in our small series may be due to sampling error, but Shaver \& Carr $(1967,1969)$ also found no pure monosomics among 274 rabbit blastocysts. Nullosomic gametes or monosomic zygotes may therefore be at a disadvantage in the rabbit. Hofsaess \& Meacham (1971) reported one monosomic and one monosomic/trisomic mosaic in the rabbit, but their finding of (apparently) 50\% heteroploid blastocysts among eighteen analysed is puzzling.

Diploid/aneuploid mosaics. These comprised four $2 \mathrm{~N} / 2 \mathrm{~N}+1$ (1 XX and $3 \mathrm{XY}$ ), and one $2 \mathrm{~N} / 2 \mathrm{~N}-1(\mathrm{XX})$, the sex chromosomes being those of the $2 \mathrm{~N}$ component. The first four all came from HS dams and were recovered in a 1-month 
period coincident with an intestinal disorder prevalent in the colony and probably viral in origin, the experimental period being 8 months. No clustering in time was noted for any other type of heteroploid.

\section{ACKNOWLEDGMENTS}

One of us (N.S.F.) is grateful to Professor D. S. Falconer for extending the hospitality of the Department of Genetics, and to the University of Edinburgh for appointment as Senior Visiting Fellow. Support was provided by The Ford Foundation, and from NIH grant HD 03822. We are indebted to $\mathrm{Mr}$ Andrew Carothers for statistical evaluation of the 'clustering' effect, and to Mrs Susan Hayter for estimation of the inbreeding coefficient. Mr V. J. Coulter provided invaluable technical assistance in all phases of the study.

\section{REFERENGES}

Ausrin, C. R. (1961) The Mammalian Egg. Blackwell Scientific Publications, Oxford.

Beatty, R. A. (1969) Genetic content and buoyant density of rabbit spermatozoa. F. Reprod. Fert. 19, 379.

Beatty, R. A. (1972) Parthenogenesis and heteroploidy in the mammalian egg. In Oogenesis, Chap. 15. Eds. J. D. Biggers and A. W. Schuetz. University Park Press, Baltimore, and Butterworths, London.

Beatry, R. A. \& Fechneimer, N. S. (1972) Diploid spermatozoa in rabbit semen and their experimental separation from haploid spermatozoa. Biol. Reprod. 7, 267.

Garr, D. H. (1971) Ghromosome studies in selected spontaneous abortions. Polyploidy in man. F. med. Genet. 8, 164.

Esnault, C. \& Ortavant, R. (1967) Origine des spermatozoides diploïdex présents dans l'éjaculat d'un taureau Charolais. Annls Biol. anim. Biochim. Biophys. 7, 25.

Fechreimer, N. S. (1971) Gytogenetic considerations in animal breeding. Annls Génét. Sel. Anim. 3, 43.

Fechieimer, N. S., Lodge, J. R. \& Miller, R. G. (1970) Sex proportion of domestic chicken at 16 hours of incubation. $\mathcal{7}$. Reprod. Fert. 23, 365.

Hansen-Melander, E. \& Melander, Y. (1971) A case of spontaneous haploidy and notes on triploiddiploid mosaics in rabbit embryos. Hereditas, 67, 83.

Hauschxa, T., Hasson, J. E., Goldstein, M. N., Koepf, G. F. \& Sandberg, A. A. (1962) An XYY man with progeny indicating familial tendency to nondisjunction. Am. F. hum. Genet. 14, 22.

Hofsaess, F. R. \& Meacham, T. N. (1971) Chromosome abnormalities of early rabbit embryos. F. exp. Zool. 177, 9 .

Issa, M., Atherton, G. W. \& Blank, G. E. (1968) The chromosomes of the domestic rabbit, Oryctolagus cuniculus. Cytogenetics, 7, 361.

Kerr, M. \& Rashad, M. N. (1966) Chromosome studies on spontaneous abortions. Am. 7. Obstet. Gynec. 94, 322.

MaFeely, R. A. (1967) Chromosome abnormalities in early embryos of the pig. F. Reprod. Fert. 13, 579.

Miller, R. G. (1971) Chromosome abnormalities in 16 to 18 hour chick embryos: a study of incidence and modes of origin. Ph.D. dissertation, The Ohio State University.

Mtller, R. C., Fechieimer, N. S. \& JaAp, R. G. (1971) Chromosome abnormalities in 16 to 18 hour chick embryos. Cytogenetics, 10, 121.

Shaver, E. L. \& GARR, D. H. (1967) Chromosome abnormalities in rabbit blastocysts following delayed fertilization. F. Reprod. Fert. 14, 415.

Shaver, E. L. \& CARR, D. H. (1969) The chromosome complement of rabbit blastocysts in relation to the time of mating and ovulation. Can. F. Genet. Cytol. 11, 287.

Vickers, A. D. (1969a) Delayed fertilization and the prenatal sex-ratio of the mouse. F. Reprod. Fert. 20, 63.

Vickers, A. D. (1969b) Delayed fertilization and chromosomal abnormalities in mouse embryos. 7. Reprod. Fert. 20, 69. 